\title{
Trees and crime in urban areas: recommendations
}

\begin{abstract}
The benefits of trees, especially in urban settings, are often limited to discussions centered on energy savings, the removal of atmospheric carbon dioxide, muting noise pollution, and storm water control. However, several studies have examined the relationship between violence and vegetation in urban areas. In fact, the relationship between trees and crime was considered as early as 1285 by King Edward when he ordered property owners to clear highway edges of trees in an attempt to reduce robberies. 1 In this paper, I will review studies on the relationship neighborhood trees have to crime and provide recommendations regarding how urban trees can assist to deter criminal activity. Recommendations resulting from reviewing these studies are: 1. Enhancing the presence of current trees and green spaces in those areas, 2. Educating citizens on the need for trees and green spaces, 3. Creating incentives for homeowners and tenants to support efforts that increase the number of and condition trees and green spaces, 4. Finding partnerships with local businesses and industry to aid in tree plantings and greening efforts.
\end{abstract}

Keywords: urban forestry, urban crime, urban ecology, urban trees
Volume 2 Issue 3 - 2018

\author{
Parker TS \\ Meeman Biological Field Station, The University of Memphis, \\ USA
}

Correspondence: Tommy S Parker, Meeman Biological Field Station, The University of Memphis, 1236 Cuba-Millington Rd, Millington, TN 38053, USA, Tel 0I+573-356-8667, Email tommysparker@gmail.com

Received: April 12, 2018 | Published: May 02, 2018

\section{Introduction}

The benefits of trees, especially in urban settings, are often limited to discussions centered on energy savings, the removal of atmospheric carbon dioxide, muting noise pollution, and storm water control..$^{2-5}$ Yet, the benefits of trees extend well beyond the environmental benefits just mentioned. In this paper, the relationship neighborhood trees have to crime and as well as recommendations from these findings will be discussed. This is pertinent given that many communities are often defined by the level of safety, be it realized or not, in that community. ${ }^{6,7}$ As a result of this, those neighborhoods deemed less safe have been shown to have lower home values when compared to similar localities. . $, 8,9^{2}$

The relationship between trees and crime was considered as early as 1285 by King Edward I when he ordered property owners to clear highway edges of trees in an attempt to reduce robberies. ${ }^{1}$ Several studies have examined the relationship between violence and vegetation in urban areas. In order to provide further explanation and to give further relevance of the approach being used, I will review a portion of these studies. The overarching goal of this paper is to provide municipal governments and agencies recommendations regarding how the use of trees in urban areas can assist with the reduction of crime.

\section{Review of Studies}

In this review I will provide information on study areas, briefly discuss the methodology employed, and the general results of the study. The subject of crime and trees has received limited investigation; therefore, a wide breadth of studies is not available for review. However, for more detailed information regarding statistical analyses in these investigations please see the referenced studies. ${ }^{7-16}$ This is not an exhaustive list of the studies that investigate this subject. However, those studies presented here are those representatives of many of the urban areas found throughout the United States.
Kuo et al. ${ }^{13}$ examined the relationship of vegetation, trees and grass, to crime in 98 apartment buildings across Chicago, Illinois, USA. The authors took numerous photographs of each apartment building from the ground and aerial vantage points in June while the tree canopy was in full leaf and grass was green. The photographs were then used to assess the level of vegetation around the various apartment complexes. To assess crime, the authors used data from the Chicago Police Department year-end Uniform Crime Reports to determine the location and types of crimes committed in each apartment complex. Crimes were categorized as property crime (thefts, vehicle thefts, burglaries, and arson), violent crime (assaults, batteries, robberies, and homicides), and total crimes (the sum of all crimes reported). Kuo et al. ${ }^{13}$ found that property crimes and violent crimes occurred less in areas with taller trees. This was also true for total crimes-areas with taller trees that did not obstruct visibility had fewer overall crimes.

In Austin, Texas, USA Snelgrove et al. ${ }^{7}$ used geographic information system (GIS) to assess the association of green spaces (trees, grass, and shrubs) to the amount and types of crimes across the city. The authors used crime data obtained from the Austin Police Department for the two months of the highest occurrences of crimes for 1995, August and September. Crimes were assigned a severity code ranging from one for capital murder, the most severe crime, to six for burglary of a no residence, the least severe crime. Crime severity was determined by the degree of punishment for each crime according to the $16^{\text {th }}$ edition of the Texas Penal Code. Results of this study, as with the results of Kuo et al. ${ }^{13}$ showed a negative correlation between greenness and crimes, with the primary component of greenness being tree cover.

Donovan et al. ${ }^{16}$ assessed the relationship between trees and crime in Portland, Oregon, USA. They examined 431 reported crimes in a sampling of 2,813 single-family homes. Crime data were obtained from the Portland Police Bureau and divided into seven categories: aggravated assault, burglary, larceny, motor-vehicle theft, robbery, simple assault, and vandalism. Tree variables evaluated were total crown area, crown height (the height at which the crown starts), number 
of trees on the lot, and tree size. It should be noted that the authors limited their analysis to single family homes because they believe the relationship between trees and crime may be fundamentally different for multiple-family homes. ${ }^{16}$ The study found that the crown area of street trees and the crown area of trees that share the lot with the home were associated with decreased crime occurrence.

The findings of the reviewed studies, ${ }^{7,13,16}$ as well as additional studies, ${ }^{8-12,14,15}$ have been similar in that areas abundant in tree cover have reduced crime rates when compared to similar areas with less tree cover. These findings, however, come with a caveat-it is the larger and taller trees that are associated with not only reduced crime rates; but also the occurrence of less violent crimes. The authors explained that it is the crown of the tree that obstructs views and provides locations for criminals to hide and larger trees have higher crowns. Additionally, the authors note that larger trees may also encourage people to spend more time outside and, with more individuals outside in a community, the probability of a criminal being observed increases. There by discouraging criminal activity.

\section{Recommendations}

Urban areas that have undesirable levels of crime may consider all or a combination of the following recommendations:

a) Enhance the presence of current trees and green spaces.

b) Educate citizens on the need for trees and green spaces.

c) Provide incentives for homeowners and residents to support efforts that increase the number of and condition trees and green spaces

d) Create partnerships with local businesses and industry to aid in tree plantings and greening efforts. These approaches encourage and assist citizens and businesses into becoming stakeholders in that community.

e) Additionally, it encourages these citizens and businesses to invest time and other resources in that community.

Enhancing the presence of current trees and green spaces can be a cost effective method to aid in the reduction crime. Many urban areas currently have green spaces in the communities, ${ }^{5}$ however, in many cases the conditions of these areas are not aesthetically pleasing. As a result of this, they can easily become areas that can harbor criminal behavior or at the very least create conditions in which criminal activity may occur. Often times improving the condition of these areas can be less costly than creating new areas for trees or new green areas. Municipal governments can invest in renewing landscaping and current structures as a means to improve tree health and the aesthetics of green spaces.

Educating citizens can serve to introduce projects and provide opportunities for participation. Many citizens are naturally curious in regards to tree plantings and other environmental activity they may observe in their community. This approach provides a platform for interaction with citizens while exploring how they can play a role in the success of the project. Take care to explain short and long term goals as well as why these goals were selected. Be transparent in regards to challenges that may arise and disclose any possible solutions. I suggest not just educating citizens, but also, including citizens in the planning process. This approach can be a highly effective method to receive input on your plans and feedback regarding past activities.
Hold education programs and activities in the community by seeking out natural gathering places within that community as a venue. In addition to being informative, it may also help to alleviate many of the problems often associated with a seemingly top down approach from the government.

Creating incentives for homeowners and residents to support efforts that increase tree plantings and care can be very advantageous. Incentives for homeowners are often only available to the homeowner regardless if that individual actually resides in the home. In cases in which the homeowner does not reside in the home but has a tenant in the property, it will be that tenant that would be the actual individual in the community in which you are trying to find support. Therefore, providing incentives to the individuals that physically resides in the community may result in better results. Therefore, extending incentives to tenants may increase the likelihood of citizen participation. Incentives may include development incentives, grants, rebates and installation financing, awards and recognition programs. ${ }^{17}$ Many municipalities focus on incentives that are specific to individual neighborhoods such as gift certificates to local businesses or restaurants.

Partnerships with local businesses and industry can be another cost effective method to increasing the amount of trees in communities. Providing opportunities to promote businesses, tax credits, or other inventive mechanisms local governments may have opportunities to provide can incentivize these partnerships. These partnerships can result in monies for the purchasing of supplies, volunteers for labor, individuals to promote and support tree planting and greening projects or a combination of these. Many businesses actively look for opportunities to improve the communities in which they serve and opportunities for community relations. Therefore, prospects for these partnerships should be present.

It is important to note that tree canopy was negatively correlated to the presence of crime, with trees with larger canopies having lower and less violent crimes. ${ }^{7,9,10,13-16}$ For newly planted trees, it may take several years to achieve the desired outcome. However, in areas that have well established trees, proper pruning and care may result in a more immediate positive result.

\section{Acknowledgements}

None

\section{Conflict of interest}

Author declares there is no conflict of interest.

\section{References}

1. Pluncknett TFT. Edward I and criminal law. UK: Cambride University Press; 1960.

2. McPherson EG, Nowak DJ, Rowntree RA. Chicago's urban forest ecosystem: results of the Chicago Urban Forest Climate Project. USA: U.S. Department of Agriculture, Forest Service, Northeastern Forest Experiment Station; 1994. p. 1-210.

3. McPherson EG, Simpson JR, Peper PJ, et al. Municipal forest benefits and costs in five U.S. cities. Journal of Forestry. 2005;103(8):411-416.

4. Nowak DJ, Crane DE, Dwyer JF. Compensatory value of urban trees in the United States. Journal of Arboriculture. 2002;28(4):194-199. 
5. Parker TS, Nilon CH. Urban landscape characteristics correlated with the synurbization of wildlife. Landscape and Urban Planning. 2012;106(4):316-325.

6. Gorham MR, Waliczek TM, Snelgrove A, et al. The impact of community gardens on numbers of property crimes in urban Houston. HortTechnology. 2009;19(2):291-294.

7. Snelgrove AG, Michael JH, Waliczek TM, et al. Urban greening and criminal behavior: a geographic information system perspective. HortTechnology. 2004;14(1):48-51.

8. Troy A, Morgan GJ. Property values, parks, and crime: a hedonic analysis in Baltimore, MD. Landscape and Urban Planning. 2008;87(3):233-245.

9. Maas J, Spreeuwenberg P, Van Winsum-Westra M, et al. Is green space in the living environment associated with people's feelings of social safety? Environment and planning A: Economy and Space. 2009;41(7):17631777.

10. Pack PHC, Salked J. The structural determinants of fear of crime: an analysis using census and crime survey data from England and Wales. International Review of Victimology. 1994;3(2):211-233.
11. Sullivan W, Kuo FE. Do trees strengthen urban communities, reduce domestic violence? Arborist News. 1996;5(2):33-34.

12. Waliczek TM, Mattson RH, Zajicek JM. Psychological benefits of community gardening. The Journal Environmental Horticulture. 1996;14(4):204-209.

13. Kuo FE, Sullivan WC. Environment and crime in the inner city-does vegetation reduce crime? Environment and Behavior. 2001;33(3):343-367.

14. Michael S, Hull R, Burch W. Environmental factors influencing auto burglary-a case study. Environment and Behavior. 2001;33(3):368-388.

15. Kuo FE. The role of arboriculture in a healthy social ecology. Journal of Arboriculture. 2003;29(3):148-155.

16. Donovan GH, Prestemon JP. The effect of trees on crime in Portland, Oregon. Environment and Behavior. 2012;44(1):3-30.

17. Environmental Protection Agency. Managing wet weather with green infrastructure: municipal handbook, incentive mechanisms. USA: United States Environmental Protection Agency; 2009. p. 1-35. 